Acta Universitatis Wratislaviensis • No 3982

Literatura i Kultura Popularna XXV, Wrocław 2019

https://doi.org/10.19195/0867-7441.25.3

\title{
Konrad Dominas
}

ORCID: 0000-0001-5120-4159

Uniwersytet im. Adama Mickiewicza w Poznaniu

\section{Supersystem rozrywkowy versus opowiadanie transmedialne, czyli słów kilka o terminologiczno-metodologicznym chaosie}

Słowa kluczowe: supersystem rozrywkowy, supersystem of transmedia intertextuality, opowiadanie transmedialne, uniwersum kulturowe, literatura i kultura popularna

Keywords: supersystem of entertainment, supersystem of transmedia intertextuality, transmedia storytelling, cultural universe, popular literature and culture

Sądzę jednak — pisze Henry Jenkins w książce Kultura konwergencji. Zderzenie starych i nowych mediów - iż nie mamy jeszcze dobrych kryteriów estetycznej oceny dzieł wykorzystujących różne media. Zbyt mało było w pełni transmedialnych opowiadań, by twórcy mogli z wystarczającą pewnością ocenić, jak wygląda najlepsze wykorzystanie tej nowej formy narracji lub by krytycy i konsumenci wiedzieli, jak rozmawiać o tym, co działa lub nie działa wewnątrz takiej marki ${ }^{1}$.

Opinia amerykańskiego badacza w kontekście studiów nad popkulturą dotyka kwestii zasadniczej — braku stosownych metod, które pozwoliłyby opisać przykłady rozmaitych produktów odnoszących się do określonego zjawiska kultury. Dla Jenkinsa takim zjawiskiem jest Matrix: „opowieść tak wielka, że nie zmieściłaby się w jednym tylko środku przekazu"2. Matrix to nie tylko bowiem trzy pełnometrażowe produkcje ${ }^{3}$, lecz także film dokumentalny The Matrix Re-

${ }^{1}$ H. Jenkins, Kultura konwergencji. Zderzenie starych i nowych mediów, przeł. M. Bernatowicz, M. Filiciak, Warszawa 2007, s. 96.

2 Ibidem, s. 95.

3 Matrix (The Matrix, reż. Lilly Wachowski i Lana Wachowski, Australia-USA 1999), Matrix Reaktywacja (The Matrix Reloaded, reż. Lilly Wachowski i Lana Wachowski, Australia-USA 2003) i Matrix Rewolucje (The Matrix Revolutions, reż. Lilly Wachowski i Lana Wachowski, Australia-USA 2003). 
visited (reż. Josh Oreck, USA 2001), trzy gry komputerowe ${ }^{4}$, Animatrix (Japonia-USA 2003) - dziewięć krótkometrażowych filmów animowanych ${ }^{5}$, książki i komiksy ${ }^{6}$ oraz niezliczona liczba gadżetów ${ }^{7}$.

W konsekwencji braku narzędzi metodologicznych rodzi się mylne przekonanie, że istotą problemu jest nie tyle opisanie, zanalizowanie czy zinterpretowanie określonego zjawiska, ile stworzenie odpowiedniej terminologii, która pozwoliłaby jedynie nazwać (albo i aż nazwać) przestrzeń nakreśloną przez badacza. Owo rozróżnienie między problematyką metodologiczną a terminologiczną można porównać do metafory zastosowanej przez Tomasza Goban-Klasa w kontekście użytkowania informacji w internecie. Krakowski badacz stosuje dwa pojęcia „surfowanie” oraz „żeglowanie"8. Surfowanie jest emocjonalne, łatwiejsze, rozrywkowe, natomiast żeglowanie — racjonalne i trudniejsze ${ }^{9}$.

Przykładem terminologicznego surfowania, nawet po najdalszych zakamarkach współczesnej popkultury, jest używanie (a niekiedy wręcz nadużywanie) dwóch pojęć będących głównym tematem niniejszego tekstu — supersystemu rozrywkowego (supersystem of entertainment) oraz opowiadania transmedialnego (transmedia storytelling $)^{10}$. Pierwsze z nich wprowadziła Marsha Kinder w książce Playing with Power in Movies, Television, and Video Games: From Muppet Babies to Teenage Mutant Ninja Turtles ${ }^{11}$. Oprócz supersystemu rozrywkowego

${ }^{4}$ Enter the Matrix (2003, prod. Shiny Entertainment, wyd. Atari/Infogrames, wyd. pol. CDP) wyprodukowana przez Davida Perry'ego; The Matrix Online (2005, prod. Monolith Productions, wyd. SEGA) według scenariusza Paula Chadwicka; The Matrix: Path of Neo (2005, prod. Shiny Entertainment, wyd. Atari/Infogrames, wyd. pol. Licomp Empirical Multimedia).

5 Polska wersja ukazała się w tym samym roku. Serię tworzą następujące tytuły: Ostatni lot Ozyrysa, Drugie odrodzenie, część I, Drugie odrodzenie, część II, Historia ucznia, Program, Rekord świata, Nawiedzony dom, Opowieść detektywa, Zniewolony. Dokładne dane na temat reżyserów i scenarzystów zob. http://www.imdb.com/title/tt0328832/ (dostęp: 26.11.2016).

${ }^{6}$ Warto zwrócić uwagę na The Art of the Matrix Spencera Lamma (Newmarket Press, 2000), Enter the Matrix: Official Strategy Guide Douga Walsha (Brady Games, 2003) oraz serię komiksów The Matrix Comics wydawanych przez Titan Books w latach 2003-2005.

7 O Matriksie w kontekście supersystemu rozrywkowego i opowiadania transmedialnego zob. K. Dominas, Tekst i jego dodatki, dodatki i tekst — od supersystemu rozrywkowego do uniwersum kulturowego, „Forum Poetyki” 2016 [jesień], http://fp.amu.edu.pl/wp-content/uploads/2016/10/ KDominas_TekstIJegoDodatkiDodatkiITekst_ForumPoetyki_jesien2016.pdf, s. 24-33.

8 T. Goban-Klas, Rwacy nurt informacji, [w:] Wartki nurt mediów. Ku nowym formom spotecznego życia informacji. Pisma z lat 2000-2011, red. T. Goban-Klas, Kraków 2011, s. 71.

9 T. Goban-Klas, Surfowanie czy żeglowanie w cyberprzestrzeni, czyli o wychowaniu człowieka medialnego i mobilnego homo internetus, [w:] Wartki nurt mediów..., s. 503.

${ }^{10} \mathrm{Na}$ temat przywołanych pojęć w polskiej literaturze przedmiotu zob. A. Mazurkiewicz, Teksty kultury cyberpunkowej w systemie rozrywkowym, „Studia Pragmalingwistyczne” 3, 2011, s. 30-50; Z. Wałaszewski, Papierowy jednorożec, klubówka i „Łowca androidów”. O powstawaniu supersystemu rozrywkowego, [w:] Literatura i kultura popularna. Badania, analizy, interpretacje, red. A. Gemra, Wrocław 2015, s. 217-230; K. Dominas, op. cit.

11 M. Kinder, Playing with Power in Movies, Television, and Video Games: From Muppet Babies to Teenage Mutant Ninja Turtles, Berkeley 1991. 
autorka używa również terminu supersystem of transmedia intertextuality ${ }^{12}$, który trafniej oddaje specyfikę omawianego przez nią materiału. Charakterystyczne dla pracy Kinder jest krótkie nawiązanie do Julii Kristevej i stosowanej przez bułgarsko-francuską badaczkę kategorii intertekstualności. Jak pisze Kinder:

Intertekstualność oznacza, że każdy pojedynczy tekst (taki rodzaj sztuki jak film lub powieść albo bardziej powszechny tekst jak artykuł w gazecie, billboard albo zwyczajna uwaga słowna) jest częścią szerszego kulturowego dyskursu i z tego powodu musi być odczytywany w relacji $\mathrm{z}$ innymi tekstami i ich rozmaitymi tekstualnymi strategiami i ideologicznymi założeniami ${ }^{13}$.

Termin transmedia intertextuality można zatem potraktować jako uzupełnienie intertekstualności o nowy system znaków: filmy, animacje, gry komputerowe, telewizję śniadaniową itp. Supersystem of transmedia intertextuality oznacza nową transmedialną przestrzeń intertekstualności, którą Kinder określa jako supersystem rozrywkowy ${ }^{14}$.

Przytoczony we wstępie Jenkins jest autorem drugiego z pojęć — „opowiadania transmedialnego" (,synergicznego") — które wyrasta z trzech podstawowych założeń teorii przywoływanego badacza: konwergencji mediów, kultury uczestnictwa oraz inteligencji zbiorowej ${ }^{15}$. Opowiadanie transmedialne łączy zatem różne platformy medialne w jeden wspólny organizm, któremu treść nadają konsumenci - użytkownicy kultury. Współpracują oni z sobą dzięki nieustannej wymianie informacji oraz collective intelligence. Warunkiem uczestnictwa w tym systemie jest ciągłe poszukiwanie i zaangażowanie w procesy wytwarzania nowych treści ${ }^{16}$.

\section{Terminologiczny miszmasz, czyli nihil novi sub sole}

Kiedy w połowie lat dziewięćdziesiątych World Wide Web uczyniła z internetu pełnoprawne medium tożsame z radiem i telewizją, przedstawiciele wielu dyscyplin naukowych prześcigali się w tworzeniu pojęć charakteryzujących nową, cyfrową technologię i odróżniających je od ówczesnej ,galaktyki Gutenberga”. Dziesiątki terminów odwołujących się w mniejszym bądź większym zakresie do spuścizny tak zwanej kanadyjskiej szkoły medioznawczej, przede wszystkim prac Marshalla McLuhana, Erica A. Havelocka, Waltera J. Onga, Derricka de

12 Ibidem, s. 1-2.

13 ,[I]ntertextuality has come to mean that any individual text (whether an artwork like a movie or novel, or a more commonplace text like a newspaper article, billboard, or casual verbal remark) is part of a larger cultural discourse and therefore must be read in relationship to other texts and their diverse textual strategies and ideological assumptions" (ibidem, s. 2; przeł. K.D.)

14 K. Dominas, op. cit., s. 28.

15 H. Jenkins, op. cit., s. 9. Zob. również http://henryjenkins.org/2006/06/welcome_to_convergence_culture.html (dostęp: 27.11.2017).

$16 \bar{K}$. Dominas, op. cit., s. 30. 
Kerckhove'a ${ }^{17}$, zaczęły wypełniać setki książek i artykułów ${ }^{18}$. Hipertekstualność, multimedialność i interaktywność odmieniane były przez wszystkie przypadki, a McLuhanowskie stwierdzenie "the medium is the message" 19 stało się punktem obowiązkowym każdej niemal teorii. Współcześnie stworzone wówczas terminy są w większości przykładami tak zwanych buzzwords — modnych powiedzonek, które nadużywane w rozmaitych kontekstach zatraciły jakiekolwiek znaczenie ${ }^{20}$. Być może to właśnie zadecydowało, że Lev Manovich podważył zasadność stosowania hipertekstualności, multimedialności i interaktywności, a na ich miejsce wprowadził nowe: reprezentację numeryczną, modularność, automatyzację, wariacyjność i transkodowanie kulturowe ${ }^{21}$. Zastosowane przez Manovicha terminy były lepiej umocowane zarówno w naukach informatycznych, jak i w licznych odniesieniach do kultury i sztuki. Zaproponowane jednak przez uczonego pojęcie nowych mediów szybko się zdezaktualizowało ${ }^{22}$. Sam autor we wstępie do The New Media Reader pod redakcją Noaha Wardripa-Fruina i Nicka Montforta rozszerza rozumienie tego terminu, definiując go między innymi jako: technologię komputerową używaną jako platforma dystrybucji; dane komputerowe sterowane przez oprogramowanie; miks istniejących konwencji kulturowych i konwencji oprogramowania ${ }^{23}$. Nowe media stały się na początku XXI wieku kategorią wręcz obowiązkową, powoli krocząc w stronę wspomnianego buzzword. Co bowiem oznacza „nowe” w odniesieniu do konkretnej cezury czasowej ${ }^{24}$, skoro przedsta-

17 Zob. D. Mersch, Teorie mediów, przeł. E. Krauss, Warszawa 2010, s. 91-130; É. Maigret, Socjologia komunikacji mediów, przeł. I. Piechnik, Warszawa 2012, s. 144-157.

18 Zob. m.in. P. Levinson, Miękkie ostrze. Naturalna historia i przyszłość rewolucji informacyjnej, przeł. H. Jankowska, Warszawa 1999; J.D. Bolter, R. Grusin, Remediation. Understanding New Media, Cambridge 2000; D. de Kerckhove, Powłoka kultury. Odkrywanie nowej elektronicznej rzeczywistości, przeł. W. Sikorski, P. Nowakowski, Warszawa 2001; C. Vandendorpe, Od papirusu do hipertekstu. Esej o przemianach tekstu i kultury, przeł. A. Sawisz, Warszawa 2008; J.D. Bolter, Przestrzeń pisma. Komputery, hipertekst i remediacja druku, przeł. M. Tabaczyński, A. Małecka, Kraków-Bydgoszcz 2014.

19 M. McLuhan, Zrozumieć media. Przedlużenia człowieka, przeł. N. Szczucka, Warszawa 2004, s. 39.

${ }^{20}$ K. Dominas, M. Kaźmierczak, A.W. Mikołajczak, Antyk w cyberprzestrzeni, Gniezno 2008, s. 21-26. Zob. również M.-L. Ryan, Transmedia storytelling: Industry buzzword or new narrative experience?, „Storyworlds: A Journal of Narrative Studies” 7, 2015, nr 2. Transmedial Worlds in Convergent Media Culture, s. 1-19.

${ }^{21}$ L. Manovich, Język nowych mediów, przeł. P. Cypryański, Warszawa 2006, s. 92-118.

${ }^{22}$ Lev Manovich zdefiniował nowe media jako „dane przekonwertowane do postaci umożliwiającej prowadzenie obliczeń — do postaci danych komputerowych”. Ibidem, s. 90.

23 Manovich pisze również o estetyce, która jest związana z wczesnym etapem każdego nowoczesnego medium oraz technologii komunikacji; szybszym wykonywaniu algorytmów, które wcześniej obliczano ręcznie lub za pomocą innych technologii; odkodowaniu modernistycznej awangardy; metamediach. Zob. idem, New media from Borges to HTML, [w:] The New Media Reader, red. N. Wardrip-Fruin, N. Montfort, Cambridge 2003, s. 16-23.

${ }^{24}$ Według autorów podręcznika Nowe media. Wprowadzenie termin „nowy” oznaczać może: nowe doświadczenia tekstualne (nowe rodzaje form gatunkowych i tekstualnych); nowe sposoby 
wiciele szkoły marksistowskiej — Bertolt Brecht i Bela Balázs — nowym medium określali kamerę filmową i radio? ${ }^{25}$ Nie powinno zatem nikogo dziwić, że Paul Levinson stworzył kategorię nowych nowych mediów i zaproponował kolejny paradygmat współczesnej kultury — przejście z epoki konsumenta (wyraźny wpływ koncepcji prosumenta Alvina Tofflera) ${ }^{26}$ do epoki aktywnego producenta informacji ${ }^{27}$. Jeśli dodamy do tego termin „Web 2.0”, jaki pojawił się po 2004 roku, akcentując społeczności internetowe, a także zbiorową kreatywność, chęć zaangażowania i otwartości oraz blogi, otrzymamy terminologiczny miszmasz, kreujący często sztuczne i trudne do zrozumienia cezury i pojęcia. Problem ten niezwykle trafnie ujmuje wypowiedź Jurija M. Łotmana:

W różnych okresach nauka wyrzuca na powierzchnię słowa takiego właśnie rodzaju, które wskutek lawinowego wzrostu ich występowania w tekstach naukowych zatracają swą niezbędną jednoznaczność. Słowa te nie tyle ściśle terminologicznie oznaczają jakieś pojęcie naukowe, ile stanowią hasło wywoławcze aktualnego problemu i wskazują na obszar, na którym się rodzą nowe idee naukowe ${ }^{28}$.

Supersystem rozrywkowy wraz z opowiadaniem transmedialnym nie tylko uzupełniają powyższą terminologię, lecz także wpisują się w problematykę zmedializowanej współcześnie kultury. O ile jednak takie pojęcia jak hipertekstualność czy interaktywność akcentowały różnice między starymi a nowymi mediami (przede wszystkich prace Davida Boltera i innych kontynuatorów kanadyjskiej szkoły medioznawczej) $)^{29}$, o tyle terminy Kinder i Jenkinsa wykorzystuje się przede wszystkim do rejestracji, klasyfikacji i nazywania wielorakich produktów kultury: filmów, gier komputerowych, gadżetów, literatury fan fiction, wypowiedzi w serwisach społecznościowych, filmów w serwisach typu YouTube i wielu innych. Metodologię zastępuje się zatem ustaleniem wspólnego mianownika dla przedmiotów należących do tego samego zbioru. W tak przyjętej koncepcji wypowiada się między innymi Natalia Wrzeszcz, która w artykule Blondynki na krańcu świata. Kobieca opowieść o Czarnym Lądzie książkom Beaty Pawlikowskiej i Martyny Wojciechowskiej nadaje status reporterskiego opowiadania transmedialnego. Według autorki „zmiana” ta jest możliwa dzięki korzystaniu z różnych środków

reprezentacji świata; nowe relacje pomiędzy podmiotami (użytkownikami i konsumentami) oraz technologiami medialnymi; nowe doświadczenia relacji pomiędzy cielesnością, tożsamością i społecznością; nowe koncepcje relacji ciała biologicznego do mediów technologicznych; nowe wzorce organizacji i produkcji. M. Lister et al., Nowe media. Wprowadzenie, przeł. M. Lorek, A. Sadza, K. Sawicka, Kraków 2009, s. 2. Zob. również T. O’Reilly, What is Web 2.0. design patterns and business models for the next generation of software, http://www.oreilly.com/pub/a/web2/archive/ what-is-web-20.html (dostęp: 27.11.2017).

25 D. Mersch, op. cit., s. 63-66, 72-74.

26 A. Toffler, Trzecia fala, przeł. E. Woydyłło, przedm. W. Osiatyński, Warszawa 1997, s. 32.

27 P. Levinson, Nowe nowe media, przeł. M. Zawadzka, Kraków 2010, s. 23.

28 J.M. Łotman, Tekst w tekście, przeł. J. Faryno, „Literatura na Świecie” 1985, nr 3, s. 325.

29 Zob. przyp. $18 \mathrm{w}$ niniejszym tekście. 
przekazu i nie miałaby miejsca, gdyby nie rozwój konwergencji ${ }^{30}$. W podobnym duchu pisze Magdalena Boczkowska, która w Opowieści transmedialnej — znaku naszych czasów poglądy Jenkinsa wykorzystuje do badań — zdaniem autorki transmedialnych powieści, takich jak chociażby Kaktus w sercu Barbary Jasnyk (W.A.B., Warszawa 2008) ${ }^{31}$. Szukanie jednej płaszczyzny odniesienia przypomina zatem algorytm składający się z trzech zadań: zgromadzenia rozmaitych przedmiotów charakteryzujących określone zjawisko, temat, rzecz itp.; pogrupowania owych przedmiotów i umieszczenia ich w pudełkach; nadania pudełkom nazw. Prześledźmy ten algorytm w odniesieniu do stosowania pojęć supersystemu rozrywkowego oraz opowiadania transmedialnego.

Gromadzenie wiedzy w XXI wieku - zdominowanym przez technologie internetowe - jest czynnością w dużej mierze mechaniczną, polegającą na znajomości obsługi wyszukiwarek internetowych (przede wszystkim Google) oraz umiejętności przeglądania informacji w serwisach społecznościowych typu Facebook, Twitter, Wikipedia, YouTube itp. Zagadnienie to niezwykle trafnie ują Alexander Halavais: „Nowoczesna wyszukiwarka przejęła obowiązki, które przedstawiciele wielu starożytnych kultur przekazywali wyroczni — rolę źródła wiedzy na temat świata i tego, kim jesteśmy"32. Jeśli Wikipedię i IMDB potraktujemy jako produkty współczesnej popkultury, działające w odniesieniu do kultury uczestnictwa oraz tak zwanej collective intelligence, to rejestrowanie różnorakich przykładów pochodzących z kultury popularnej możemy oddać w ręce społeczności internetowej. Społeczność ta nie tylko kolekcjonuje owe przykłady, lecz także ukazuje stopień zainteresowania nimi — stopień popularności, wyznaczający informacji nowy, cyfrowy status ${ }^{33}$. Oczywiście nie jest to wiedza w rozumieniu naukowym,

30 N. Wrzeszcz, Blondynki na krańcu świata. Kobieca opowieść o Czarnym Ladzie, „Annales Universitatis Paedagogicae Cracoviensis. Studia de Cultura” 5, 2013, s. 203-214.

31 M. Boczkowska, Opowieść transmedialna — znak naszych czasów, „Postscriptum Polonistyczne" 2014, nr 2 (14), s. 125-137. W opozycji do przytoczonych w tekście prac warto zaznaczyć opinię Anity Has-Tokarz: „W obszarze komercyjnego systemu medialnego książka adresowana do młodych odbiorców funkcjonuje jako produkt marketingowy, podlegając charakterystycznym dla rynku strategiom promocji i reklamy” (eadem, ,, Monster High” jako transmedialna opowieść —od książki do monsterhighmanii, „Literatura i Kultura Popularna” 19, 2013, s. 29). Warto również powołać się na ciekawe rozróżnienie między opowieścią transmedialną a konceptem transmedialnego transferu, zastosowane przez Dominikę Kozerę. Zob. eadem, Zabawa w transmedia: Trasmedialność opowieści jako wymóg współczesnej kultury, „Kultura i Historia” 2016, nr 29, http://www. kulturaihistoria.umcs.lublin.pl/archives/5736 (dostęp: 17.12.2017). Artykuły Wrzeszcz i Boczkowskiej są dowodem braku odpowiedniej metody i zastępowania jej terminologicznym opakowaniem (poglądy Jenkinsa), które zamiast wyjaśniać, dodatkowo komplikuje i tak już problemowo bogatą przestrzeń nakreśloną przez autorki.

32 A. Halavais, Wyszukiwarki internetowe a społeczeństwo, przeł. T. Płudowski, Warszawa 2012, s. 15.

33 Zob. K. Dominas, Cezar w nowych mediach - recepcja literatury antycznej czy analiza wybranych tematów literatury popularnej?, [w:] Związki i rozwiązi. Relacje kultury i literatury popularnej ze starymi i nowymi mediami, red. A. Gemra, H. Kubicka, Wrocław 2012, s. 203-209; 
kojarzonym z tradycyjną biblioteką i książką, ale z podstawowymi założeniami Pierre'a Leviego: „nikt z nas nie może wiedzieć wszystkiego, ale każdy z nas ma jakąś wiedzę"34.

W zakresie klasyfikacji (rejestrowania i grupowania produktów) oraz nadawania nazw sklasyfikowanym przedmiotom warto odwołać się do podstawowych założeń architektury informacji. Według Louisa Rosenfelda i Petera Morville’a jest ona połączeniem sposobu organizacji i etykietowania danych oraz schematów przeszukiwania w systemie informacyjnym ${ }^{35}$. W przytoczonym algorytmie mamy więc do czynienia z uporządkowaniem oraz oznaczaniem przedmiotów kultury. Zgodnie z tym podejściem system organizacyjny określa sposoby dzielenia jej na kategorie i jest w rzeczywistości szukaniem odpowiedniego schematu, czyli wspólnych cech obiektów tworzących zawartość i wpływających na ich logiczne grupowanie $^{36}$. Dla produktów kultury popularnej jest to schemat niejednoznaczny. Oznacza to, że rejestrowanie poszczególnych przykładów jest czynnością polegającą na wyodrębnieniu środka (jądra) danego zjawiska, a następnie dopasowywaniu do tego jądra kolejnych przedmiotów na zasadzie podobieństwa lub wspólnych właściwości. Takim środkiem zbioru może być na przykład postać z komiksu, gry wideo, filmu itp.

Kolejny proces - etykietowanie danych — określa sposoby reprezentowania informacji ${ }^{37}$. Jego podstawą powinny być konsekwencja i jednorodność. Warto zatem się zastanowić, czy nazwanie produktów zgromadzonych na przykład wokół postaci Batmana supersystemem rozrywkowym jest współcześnie adekwatne do opisywanego zjawiska. Kinder wprowadziła to pojęcie w 1991 roku, gdy nowe media dopiero co torowały sobie drogę do globalnej gospodarki: World Wide Web powstała w 1989 roku; pierwszej przeglądarki internetowej — Mosaic — zaczęto używać od 1993 roku; w 1995 roku Federalna Rada Sieci Komputerowych wprowadziła pierwszą definicję Internetu; Google opracowano w 1997 roku $^{38}$. Sam termin „supersystem rozrywkowy” jest również wieloznaczny i niejednorodny, co znajduje odzwierciedlenie w niezwykle pojemnych znaczeniowo terminach ,systemu” i „rozrywki”. Już pobieżna lektura artykułów Ryszarda Nycza, Jurija M. Łotmana, Gérarda Genette’a czy Michała Głowińskiego wskazuje ${ }^{39}$, jak skompli-

idem, Internet jako nowa przestrzeń recepcji literatury i kultury antycznej, Poznań 2017, https:// repozytorium.amu.edu.pl/handle/10593/17771, s. 19-26.

${ }^{34}$ H. Jenkins, op. cit., s. 9. O pojęciu inteligencji zbiorowej zob. R. Maciąg, Pragmatyka Internetu. Web 2.0 jako środowisko, Kraków 2013, s. 143-145.

${ }^{35}$ L. Rosenfeld, P. Morville, Architektura informacji w serwisach internetowych, przeł. K. Masłowski, T. Jarzębowicz, Gliwice 2003, s. 20.

36 Ibidem, s. 79-85.

37 Ibidem, s. 20.

38 Zob. K. Dominas, Tekst i jego dodatki..., s. 28, przyp. 19.

39 Z bogatej literatury obejmującej zagadnienie intertekstualności zob. G. Genette, Palimpsesty. Literatura drugiego stopnia, przeł. A. Milecki, [w:] Współczesna teoria badań literackich za granica, oprac. H. Markiewicz, t. 4, cz. 2, Kraków 1992, s. 316-366; M. Głowiński, O intertekstu- 
kowanym i niejednoznacznym określeniem jest „intertekstualność”. Przenoszenie jej z płaszczyzny tekstologicznej na płaszczyznę kulturowo-medialną wymaga wielkiej uwagi i precyzji terminologicznej. Być może przyczynami popularności tego pojęcia były zatem pojemność znaczeniowa poszczególnych wyrażeń oraz łacińskie przedrostki. W wyrażeniu supersystem of transmedia intertextuality mamy ich aż trzy: super-, trans- i inter-. Każdy z nich odwołuje się do odmiennego położenia w przestrzeni: super- oznacza miejsce „nad”, „ponad”, „powyżej czegoś”, trans- znaczy „,z drugiej strony czegoś”, „za czymś”, natomiast inter- — „między”, ,pomiędzy”, „wśród”, „pośród”, „w obrębie”40.

\section{Mikro- i makropodejście badawcze}

Rejestrowanie i klasyfikowanie rozmaitych przedmiotów kultury powinno być nie tyle metodą, ile wstępem do poważnej analizy zjawiska, a nadawanie nazw utworzonym zbiorom - jej konsekwencją. Takie założenie generuje dwa podejścia badawcze, które ze względu na zakres materiału można określić jako mikro- i makropodejście. Pierwsze z nich opiera się na połączeniu określonej grupy przedmiotów, a następnie ich opisaniu i interpretacji ${ }^{41}$. Powstały w ten sposób zbiór można odnieść do procesów zachodzących na przykład we współczesnej kulturze i literaturze. Głównym procesem jest w tym wypadku nie tyle klasyfikowanie czy rejestrowanie przedmiotów, jak w przedstawionym algorytmie, ile zwrócenie uwagi na najważniejsze mechanizmy — kulturowe, medialne, społeczne, gospodarcze, odpowiedzialne za gromadzenie się elementów w zbiorze wokół konkretnego jądra, głównego punktu odniesienia. Dla postaci Batmana (istoty zbioru) będą nim wszystkie produkty nawiązujące do superbohatera: filmy, animacje, gry, gadżety, zabawki itp. Łączenie się produktów możemy wówczas przedstawić za pomocą konkretnych mechanizmów: medialnych — zespolenie różnych przestrzeni życia produktu jako jeden z elementów konwergencji; marketingowo-reklamowych - tworzenie kolejnych przedmiotów, ich konsumpcja i dystrybucja; kulturowych — zaangażowanie społeczności (kultura uczestnictwa) w powstawanie produktów. Mechanizmy te rzadko działają samodzielnie, zazwyczaj mamy do czynienia z ich współwystępowaniem, na przykład w zakre-

alności, „Pamiętnik Literacki” 77, 1996, z. 4, s. 75-100; J.M. Łotman, op. cit., s. 325-343; R. Nycz, Intertekstualność i jej zakresy. Teksty, gatunki, światy, [w:] idem, Tekstowy świat. Poststrukturalizm a wiedza o literaturze, Kraków 2000, s. 78-109.

40 Znaczenie słów na podstawie Słownik łacińsko-polski, t. 1-5, red. M. Plezia, Warszawa 2007.

41 Zob. m.in. Z. Wałaszewski, op. cit.; R. Kochanowicz, Kulturotwórcza rola uniwersów fantastycznych z gier komputerowych na przyktadzie serii ,, The Elder Scrolls”, [w:] Literatura i kultura popularna..., s. 203-216. 
sie konsumpcji i dystrybucji produktów możemy wskazać czynniki kulturowe odpowiedzialne za te właśnie procesy ${ }^{42}$.

Makropodejście badawcze jest próbą połączenia wielu zbiorów w jeden kulturowy schemat i zastanowienia się, czy dla tak powstałego organizmu można wyodrębnić określoną liczbę mechanizmów. To na tym właśnie poziomie możemy mówić o uniwersach, takich jak: Marvel, Lego, DC Comics, Star Wars i wiele innych. Niezrozumienie podstawowych mechanizmów współczesnej kultury akcentuje Mirosław Filiciak we wstępie do Kultury konwergencji. Pisze: „Brak nam świadomości mechanizmów rządzących współczesnymi przemysłami kultury, brak nam wiedzy i znajomości procesów, w których niemal wszyscy uczestniczymy jako konsumenci” ${ }^{43}$. Niewielu dziś miłośników Lego zdaje sobie na przykład sprawę, że podjęcie przez duńską firmę współpracy z Marvelem i DC Comics (klocki z serii „Lego Super Heroes”, gry „Lego Marvel Super Heroes” i wiele innych) nie wynika wyłącznie z potrzeb rynkowych czy odwzorowywania mechanizmów znanych chociażby z uniwersum Transformers, lecz jest konsekwencją zmian prawnych. Otóż w 2008 roku firma Lego straciła wyłączność na kształt klocków zgodnie z orzeczeniem Sądu Pierwszej Instancji Wspólnot Europejskich z dnia 12 listopada 2008 roku $^{44}$. Współpraca zatem z największymi światowymi firmami pozwoliła przedsiębiorstwu przenieść punkt ciężkości z ochrony patentów technicznych na ochronę własności intelektualnej, jaką są produkty Marvela czy uniwersum Gwiezdnych wojen.

\section{„Kanoniczność" produktów kultury}

Podczas „Galaktycznego Uniwersytetu”, dwóch konferencji zorganizowanych na Uniwersytecie im. Adama Mickiewicza w Poznaniu w 2016 i 2017 roku ${ }^{45}$, niejednokrotnie wśród fanów jednego z najbardziej rozpoznawalnych produktów popkultury pojawiały się spory, czy dany produkt można zakwalifikować do uniwersum Gwiezdnych wojen. Innymi słowy, czy omawiana postać, fragment

42 Warto w tym kontekście odwołać się do pojęcia reklamy transmedialnej, która w opinii Katarzyny Zych powinna być zachętą do poszukiwania kolejnych wiadomości na temat danej firmy. Każde wykorzystywane w ramach konwergencji medium ,powinno mieć odrębny wkład w rozumienie cyfrowego świata tworzonego wokół brandu" (pisownia oryginalna). K. Zych, Produkt transmedialny, czyli jak aktywizować konsumentów, http://www.biznes-firma.pl/produkt-transmedialny-czyli-jak-aktywizowac-konsumentow/15625 (dostęp: 17.12.2017). Zob. również D. Jakus, K. Zubčić, Marketing transmedialny i nowa koncepcja public relations, „Marketing Instytucji Naukowych i Badawczych" 2016, nr 4 (22), s. 92-102.

43 M. Filiciak, Kultura bliska ciatu, [w:] H. Jenkins, op. cit., s. XIII.

$44 \mathrm{http} / /$ curia.europa.eu/juris/document/document.jsf?text=\&docid=68250\&pageIndex$=0 \&$ doclang $=$ PL\&mode $=1$ st\&dir=\&occ=first\&part=1\&cid=222366 (dostęp: 27.11.2017).

45 Konferencje zostały zorganizowane przez sekcję „Amici Antiquitatis” Studenckiego Koła Naukowego Historyków im. Gerarda Labudy przy Wydziale Historycznym UAM 2-3 marca 2016 roku oraz 24-25 marca 2017 roku w Poznaniu. 
opowieści itp. jest częścią podstawową zbioru czy też nie, a jeśli nie, to z jakiego powodu. Warto zaznaczyć, że sama próba zdefiniowania uniwersum była podczas paneli tematycznych niezwykle trudna i skomplikowana, a dla postronnego słuchacza, kojarzącego sagę głównie z filmami, wręcz niezrozumiała. Dyskusje uczestników przypominały rozważania na temat kanoniczności wielkich opowieści mitycznych ${ }^{46}$, podczas gdy współcześnie dyskusja toczy się wokół genezy i struktury mitu 47 .

Porównanie do przestrzeni mitycznej i jej struktury nie jest przypadkowe. Marcin Klik, omawiając w Teoriach mitu. Wspótczesnym literaturoznawstwie francuskim (1969-2010) metodę strukturalną Claude'a Lévi-Straussa ${ }^{48}$, przytacza metaforę autobiografii zastosowaną przez francuskiego badacza Pierre'a Smitha. Otóż badanie mitu przypomina według niego pisanie autobiografii. Dla strukturalistów znaczenie ma nie dobór poszczególnych fragmentów naszego życia, lecz sposób, $\mathrm{w}$ jaki łączą się one z sobą ${ }^{49}$. Jeśli chcielibyśmy napisać biografię współczesnej popkultury, również musielibyśmy wybrać najważniejsze fragmenty jej dotychczasowej egzystencji. Co jednak byłoby kluczem do jej zrozumienia - sam dobór fragmentów czy też zasady ich łączenia? Być może zatem badanie rozmaitych uniwersów kultury ma sens jedynie w odniesieniu do ich struktury, podobnie jak w koncepcji McLuhana, w której to nie treść, lecz sam przekaz ma największe znaczenie $^{50}$.

Współcześnie większość produktów kultury wykazuje tendencje do łączenia się w większe zbiory, a przeglądanie i kolekcjonowanie owych zbiorów wydaje się niekończącą się zabawą (grą). W ramach prowadzonego przeze mnie fakultetu Współczesna kultura jako supersystem rozrywkowy studenci Wydziału Filologii Polskiej i Klasycznej Uniwersytetu im. Adama Mickiewicza w Poznaniu zaproponowali następujące supersystemy rozrywkowe: Angry Birds, powieść Władca Pierścieni Johna R.R. Tolkiena, współczesne kampanie wyborcze, serial Miasteczko Twin Peaks (Twin Peaks, reż. David Lynch, Mark Frost, USA 19901991,), serial Gra o tron (Game of Thrones, reż. David Benioff, D.B. Weiss, USA 2011-2019) ${ }^{51}$. Dla młodszych widzów najnowsze odsłony Gwiezdnych wojen, jak choćby totr 1. Gwiezdne wojny - historie (Rogue One: A Star Wars Story, reż. Gareth Edwards, USA 2016), mogą być zaledwie zachętą do kupna nowej

46 Jako przykład warto odnieść się do rozważań Stanisława Stabryły na temat mitu o Eneaszu. Zob. idem, Wergiliusz. Świat poetycki, Wrocław 1987, s. 171-177; idem, Wstęp, [w:] Wergiliusz, Eneida, przeł. T. Karyłowski, Wrocław 2004, s. LX-LXVI.

47 Zob. C. Lévi-Strauss, Antropologia strukturalna, przeł. K. Pomian, Warszawa 1970, s. 189, 195, 197; E. Mieletinski, Poetyka mitu, przeł. J. Dancygier, przedm. M.R. Mayenowa, Warszawa 1981, s. 96-122.

48 M. Klik, Teorie mitu. Wspótczesne literaturoznawstwo francuskie (1969-2010), Warszawa 2016, s. 77-81.

49 Zob. ibidem, s. 78; przyp. 10.

50 M. McLuhan, op. cit., s. 50

51 Zajęcia były prowadzone w roku akademickim 2015/2016. 
figurki lub nowego zestawu klocków Lego. I odwrotnie. Wprowadzenie nowego typu żołnierza w filmowe uniwersum Star Wars może być spowodowane potrzebami konsumentów i nie wykazywać cech wspólnych z fabułą produkcji.

Poszczególne mechanizmy popkultury układają się w swoisty system naczyń połączonych. Dla konsumentów, używających przedmiotów na przykład do zabawy, ów system ma znaczenie drugorzędne, natomiast dla badaczy współczesnej kultury tego typu przemiany stają się niezwykle istotne. Być może zatem poszczególne supersystemy rozrywkowe, opowiadania transmedialne i uniwersa kulturowe różnią się wyłącznie długością życia (funkcjonowania) poszczególnych produktów składających się na określony zbiór. To jednak nie nazwanie tego zbioru powinno być celem, lecz uchwycenie najważniejszych mechanizmów (przyczyn i skutków) procesów zachodzących we współczesnej kultury.

\section{Bibliografia}

\section{Teksty}

Lamm S., The Art of the Matrix, Newmarket Press, 2000.

Walsh D., Enter the Matrix: Official Strategy Guide, Brady Games, 2003.

\section{Opracowania}

Boczkowska M., Opowieść transmedialna - znak naszych czasów, „Postscriptum Polonistyczne” 2014, nr 2 (14), s. 125-137.

Bolter J.D., Przestrzeń pisma. Komputery, hipertekst i remediacja druku, przeł. M. Tabaczyński, A. Małecka, Korporacja Ha!art, Kraków-Bydgoszcz 2014.

Bolter J.D., Grusin R., Remediation. Understanding New Media, MIT Press, Cambridge 2000.

Dominas K., Cezar w nowych mediach - recepcja literatury antycznej czy analiza wybranych tematów literatury popularnej?, [w:] Zwiazki i rozwiązi. Relacje kultury i literatury popularnej ze starymi i nowymi mediami, red. A. Gemra, H. Kubicka, Pracownia Literatury i Kultury Popularnej oraz Nowych Mediów, Wrocław 2012, s. 203-209.

Dominas K., Internet jako nowa przestrzeń recepcji literatury i kultury antycznej, Pracownia Humanistycznych Studiów Interdyscyplinarnych, Poznań 2017.

Dominas K., Kaźmierczak M., Mikołajczak A.W., Antyk w cyberprzestrzeni, Collegium Europaeum Gnesnense, Gniezno 2008.

Genette G., Palimpsesty. Literatura drugiego stopnia, przeł. A. Milecki, [w:] Współczesna teoria badań literackich za granica, oprac. H. Markiewicz, t. 4, cz. 2, Wydawnictwo Literackie, Kraków 1992.

Gerard G., Palimpsesty. Literatura drugiego stopnia, przeł. A. Milecki, [w:] Współczesna teoria badań literackich za granica, oprac. H. Markiewicz, t. 4, cz. 2, Wydawnictwo Literackie, Kraków 1992, s. 316-366.

Głowiński M., O intertekstualności, „Pamiętnik Literacki” 77, 1996, z. 4, s. 75-100.

Goban-Klas T., Rwący nurt informacji, [w:] Wartki nurt mediów. Ku nowym formom społecznego życia informacji. Pisma z lat 2000-2011, red. T. Goban-Klas, Universitas, Kraków 2011, s. $67-73$. 
Goban-Klas T., Surfowanie czy żeglowanie w cyberprzestrzeni, czyli o wychowaniu człowieka medialnego i mobilnego homo internetus, [w:] Wartki nurt mediów. Ku nowym formom społecznego życia informacji. Pisma z lat 2000-2011, red. T. Goban-Klas, Universitas, Kraków 2011, s. $501-509$.

Halavais A., Wyszukiwarki internetowe a społeczeństwo, przeł. T. Płudowski, Wydawnictwo Naukowe PWN, Warszawa 2012.

Has-Tokarz A., ,,Monster High” jako transmedialna opowieść — od książi do monsterhighmanii, „Literatura i Kultura Popularna” 19, 2013, s. 29-38.

Jakus D., Zubčić K., Marketing transmedialny i nowa koncepcja public relations, „Marketing Instytucji Naukowych i Badawczych" 2016, nr 4 (22), s. 92-102.

Jenkins H., Kultura konwergencji. Zderzenie starych i nowych mediów, przeł. M. Bernatowicz, M. Filiciak, Wydawnictwo Akademickie i Profesjonalne, Warszawa 2007.

Kerckhove D. de, Powłoka kultury. Odkrywanie nowej elektronicznej rzeczywistości, przeł. W. Sikorski, P. Nowakowski, Mikom, Warszawa 2001.

Kinder M., Playing with Power in Movies, Television, and Video Games: From Muppet Babies to Teenage Mutant Ninja Turtles, University of California Press, Berkeley 1991.

Klik M., Teorie mitu. Współczesne literaturoznawstwo francuskie (1969-2010), Wydawnictwa Uniwersytetu Warszawskiego, Warszawa 2016.

Kochanowicz R., Kulturotwórcza rola uniwersów fantastycznych z gier komputerowych na przykladzie serii „The Elder Scrolls”, [w:] Literatura i kultura popularna. Badania, analizy, interpretacje, red. A. Gemra, Pracownia Literatury i Kultury Popularnej oraz Nowych Mediów, Wrocław 2015, s. 203-216.

Levinson P., Miękkie ostrze. Naturalna historia i przyszłość rewolucji informacyjnej, przeł. H. Jankowska, Muza SA, Warszawa 1999.

Levinson P., Nowe nowe media, przeł. M. Zawadzka, Wydawnictwo WAM, Kraków 2010.

Lévi-Strauss C., Antropologia strukturalna, przeł. K. Pomian, PIW, Warszawa 1970.

Lister M., Dovey J., Giddins S., Grant I., Kieran K., Nowe media. Wprowadzenie, przeł. M. Lorek, A. Sadza, K. Sawicka, Wydawnictwo Uniwersytetu Jagiellońskiego, Kraków 2009.

Łotman J., Tekst w tekście, przeł. J. Faryno, „Literatura na Świecie” 1985, nr 3, s. 325-343.

Maciąg R., Pragmatyka Internetu. Web 2.0 jako środowisko, Wydawnictwo Uniwersytetu Jagiellońskiego, Kraków 2013.

Maigret É., Socjologia komunikacji mediów, przeł. I. Piechnik, Oficyna Naukowa, Warszawa 2012.

Manovich L., Język nowych mediów, przeł. P. Cypryański, Wydawnictwa Akademickie i Profesjonalne, Warszawa 2006.

Manovich L., New media from Borges to HTML, [w:] The NewMediaReader, red. N. Wardrip-Fruin, Nick Montfort, MIT Press, Cambridge 2003, s. 16-23.

Mazurkiewicz A., Teksty kultury cyberpunkowej w systemie rozrywkowym, „Studia Pragmalingwistyczne" 3, 2011, s. 30-50.

McLuhan M., Zrozumieć media. Przedłużenia człowieka, przeł. N. Szczucka, Wydawnictwa Naukowo-Techniczne, Warszawa 2004.

Mersch D., Teorie mediów, przeł. E. Krauss, Wydawnictwo „Sic!”, Warszawa 2010.

Mieletinski E., Poetyka mitu, przeł. J. Dancygier, przedm. M.R. Mayenowa, PIW, Warszawa 1981.

Nycz R., Intertekstualność i jej zakresy. Teksty, gatunki, światy, [w:] idem, Tekstowy świat. Poststrukturalizm a wiedza o literaturze, Wydawnictwo IBL, Kraków 2000, s. 78-109.

Rosenfeld L., Morville P., Architektura informacji w serwisach internetowych, przeł. K. Masłowski, T. Jarzębowicz, Wydawnictwo Helion, Gliwice 2003.

Ryan M.-L., Transmedia Storytelling. Industry Buzzword or New Narrative Experience?, „Storyworlds: A Journal of Narrative Studies" 2015, nr 2, s. 1-19.

Słownik łacińsko-polski, red. M. Plezia, t. 1-5, PWN, Warszawa 2007.

Literatura i Kultura Popularna 25, 2019

(C) for this edition by CNS 
Stabryła S., Wstęp, [w:] Wergiliusz, Eneida, przeł. T. Karyłowski, Ossolineum, Wrocław 2004, s. III-CXXII.

Toffler A., Trzecia fala, przeł. E. Woydyłło, przedm. W. Osiatyński, PIW, Warszawa 1997.

Vandendorpe Ch., Od papirusu do hipertekstu. Esej o przemianach tekstu i kultury, przeł. A. Sawisz, Wydawnictwa Uniwersytetu Warszawskiego, Warszawa 2008.

Wałaszewski Z., Papierowy jednorożec, klubówka i „, Łowca androidów”. O powstawaniu supersystemu rozrywkowego, [w:] Literatura i kultura popularna. Badania, analizy, interpretacje, red.

A. Gemra, Pracownia Literatury i Kultury Popularnej oraz Nowych Mediów, Wrocław 2015, s. $217-230$.

Wrzeszcz N., Blondynki na krańcu świata. Kobieca opowieść o Czarnym Lądzie, „Annales Universitatis Paedagogicae Cracoviensis. Studia de Cultura" 5, 2013, s. 203-214.

\section{Filmografia}

Animatrix, Japonia-USA 2003.

Matrix (The Matrix), reż. L. Wachowski, L. Wachowski, Australia-USA 1999.

Matrix Reaktywacja (The Matrix Reloaded), reż. L. Wachowski, L. Wachowski, Australia-USA 2003.

Matrix Revisited, reż. J. Oreck, USA 2001.

Matrix Rewolucje (The Matrix Revolutions), reż. L. Wachowski, L. Wachowski, Australia-USA 2003.

\section{Gry komputerowe}

Enter the Matrix, prod. Shiny Entertainment, wyd. Atari/Infogrames, wyd. pol. CDP, 2003.

The Matrix Online, prod. Monolith Productions, wyd. SEGA, 2005.

The Matrix: Path of Neo, prod. Shiny Entertainment, wyd. Atari/Infogrames, wyd. pol. Licomp Empirical Multimedia, 2005.

\section{Komiksy}

The Matrix Comics, Titan Books 2003-2005.

\section{Źródła internetowe}

Dominas K., Tekst i jego dodatki, dodatki i tekst — od supersystemu rozrywkowego do uniwersum kulturowego, ,Forum Poetyki” 2016 [jesień], s. 24-33, http://fp.amu.edu.pl/wp-content/ uploads/2016/10/KDominas_TekstIJegoDodatkiDodatkiITekst_ForumPoetyki_jesien2016. pdf (dostęp: 14.02.2017).

Kozera D., Zabawa w transmedia: Trasmedialność opowieści jako wymóg współczesnej kultury, „Kultura i Historia” 2016, nr 29, http://www.kulturaihistoria.umcs.lublin.pl/archives/5736 (dostęp: 17.12.2017).

O'Reilly T., What is Web 2.0. Design patterns and business models for the next generation of software, http://www.oreilly.com/pub/a/web2/archive/what-is-web-20.html (dostęp: 27.11.2017).

Zych K., Produkt transmedialny, czyli jak aktywizować konsumentów, http://www.biznes-firma.pl/ produkt-transmedialny-czyli-jak-aktywizowac-konsumentow/15625 (dostęp: 17.12.2017). 


\title{
Entertainment supersystem versus transmedia story, that is, a few words on the terminological and methodological chaos
}

\author{
Summary
}

The aim of the article is to present two concepts - the supersystem of entertainment (supersystem of transmedia intertextuality) and the transmission of storytelling - in the context of the research problem on various examples in pop culture. The first term was introduced by Marsha Kinder in the work Playing with Power in Movies, Television, and Video Games: From Muppet Babies to Teenage Mutant Ninja Turtles, the second was by Henry Jenkins in Convergence Culture. Where Old and New Media Collide. The analysis of the above terms uses knowledge in the field of architecture of information (knowledge sharing and classification), internet technologies (search engine algorithms) and literature and popular culture (cultural universum). In addition, the most important mechanisms (causes and effects) of processes - cultural, media, social, economic - take place in contemporary culture. 